\title{
Post Deposition Annealing Effects on Optical, Electrical and Morphological Studies of ZnTTBPc Thin Films
}

\author{
B. R. REJITHA* AND C. S. MENON \\ School of Pure and Applied Physics, Mahatma Gandhi University \\ Priyadarshini Hills, Kottayam, Kerala 686 560, India. \\ k.rejitha@gmail.com \\ csmenon@gmail.com
}

Received 8 August 2011; Accepted 10 October 2011

\begin{abstract}
Phthalocyanines (Pcs) act as efficient absorbants of photons in the visible region, specifically between 600 and $700 \mathrm{~nm}$. It will produce an excited triplet state. In this paper we report the annealing effects of optical, electrical and surface morphological properties of thermal evaporated Zinc-tetra-tertbutyl-29H, 31H phthalocyanine (ZnTTBPc) thin films. The optical transmittance measurements were done in the visible region $(400-800 \mathrm{~nm})$ and, films were found to be absorbing in nature. From spectral data the absorption coefficient $\alpha$, dielectric constant $\varepsilon$ and the extinction coefficient $\mathrm{k}$ were evaluated and, results discussed. Also the optical band gap of the material was estimated. The activation energies were measured. Scanning electron microscopic studies was carried out to determine surface uniformity of films.
\end{abstract}

Key words: Thermal evaporation, phthalocyanines, band gap energy, dielectric constant, conductivity, surface morphology.

\section{Introduction}

Metal phthalocyanines have properties such as their thermal and chemical stability, ability to form well-ordered thin films and wide absorption band within optical region. This makes them very attractive for applications in optical logic display devices [1], electrophotography, solar cells [2, 3], sensitizes and colour filters [4] and optical recording [5]. They can easily be sublimed to get pure thin films without decomposition. Due to their strong absorption in the ultraviolet and visible region, phthalocyanine and its metal complexes are considered as 
electrophotographic material [6], optical recording media [7],non linear optical materials[8],organic light emitting diodes[9] and Schottky diodes[10].

Various workers have studied the basic properties of many of the metallophthalocyanines (MPcs) in detail[11-13]. Zinc phthalocyanine is the most interesting one and has been intensively studied. This material is reported to be superior to other metal substituted phthalocyanines in terms of sensitivity, reproducibility, response and recovery times in detection of gases. The better recovery characteristics of ZnTTBPc relates to its loosely packed structure (larger lattice spacing), which makes easier for the deeply adsorbed gas molecules to desorbs and discharge. A few years ago, metal porphyrin complexes have been reported for applications to gas sensing materials [14-15].

Peripheral substitution in $\mathrm{Pc}$, which is rather insoluble in organic solvents, provides a method of enhancing solubility of Pc. Four tert -butyl (tBu) groups are added to four periphery benzene rings of Zinc(II) phthalocyanine, which gives the planar molecules a three-dimensional structure tert-Butyl groups. This is widely used as a substituent to design functional molecules, enhance solubility, improve chemical stability, and light fastness of organic molecules[16]. Figure 1 shows the molecular structure of ZnTTBPc thin films.

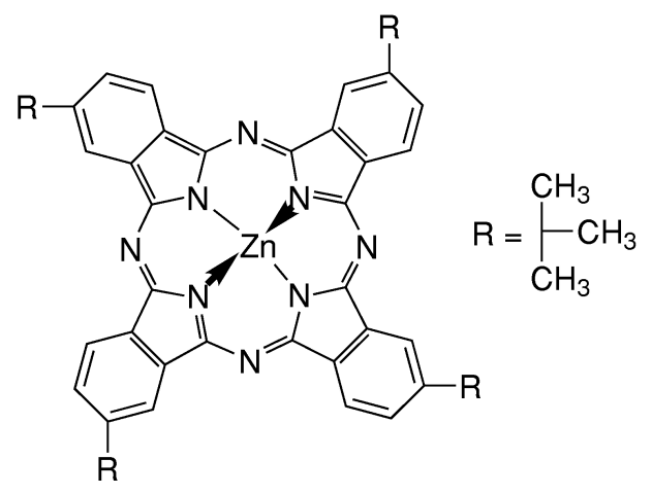

Figure 1. Molecular structure of ZnTTBPc thin films.

It is known that tert-butyl substitutes are very bulky. They can prevent coplanar $\pi-\pi$ interaction between phthalocyanine molecules and influence on crystalline polymorphic state of the metallophthalocyanine molecules.

\section{Materials and Measurements}

ZnTTBPc thin film was prepared by vacuum sublimation of ZnTTBPc powder procured from Aldrich USA. Thin film deposition was done at room temperature onto precleaned glass plates kept at a base pressure of $4 \times 10^{-5}$ Torr using the Hind Hivac 12 A4 coating unit. The evaporation was carried out by resistive heating of ZnTTBPc powder from a molybdenum boat and the deposition rate was kept constant between 10 and $12 \mathrm{~nm} / \mathrm{min}$. The films were annealed at four different annealing temperatures- 323, 373, 473 and $523 \mathrm{~K}$ for 
one hour in air. Thickness of the film was determined by Tolansky's multiple beam interference technique [17].

Optical characterization was done using UV-Vis-NIR absorption and reflection spectroscopy (model: JASCO V570) over a range of 300-900 $\mathrm{nm}$. The electrical study was done using a programmable Keithley electrometer (model no.617) for all the annealed samples. For ohmic contact vacuum deposited silver, with an inter-electrode distance of $1 \mathrm{~cm}$ was used. To avoid any possible contamination, conductivity measurements were performed in vacuum and in a dark chamber to reduce the photoconductive contribution of the molecules. The morphological studies were done by scanning electron microscopy (SEM, model: JEOL 5400).

\section{Results and Discussion}

\section{Optical characterization}

Figure 2 shows the absorbance versus wavelength of ZnTTBPc thin film. It was found that all films showed identical absorption coefficient patterns and there was no systematic change with respect to the annealing temperature. The film annealed at $323 \mathrm{~K}$ exhibited lowest absorbance while the ZnTTBPc film annealed at $373 \mathrm{~K}$ showed the highest absorbance. This was due to the different percentage loss of the unstable morphology layer on the ZnTTBPc film during the annealing process. In absorption spectra we got two bands. The Q-band was obtained in the region 550 to $712 \mathrm{~nm}$ while the $\mathrm{B}$ band is in the region 300 to $400 \mathrm{~nm}$. The Q-band showed two shoulder peaks while the B-band showed only one. This is in a good agreement with the results obtained by other researchers [17]. The Q-band corresponds to the excitation between the ground state $\pi$ (HOMO) to the $\pi^{*}$ (LUMO) [18]. Optical band gap values were obtained from analysis of the absorption spectrum in high energy region.

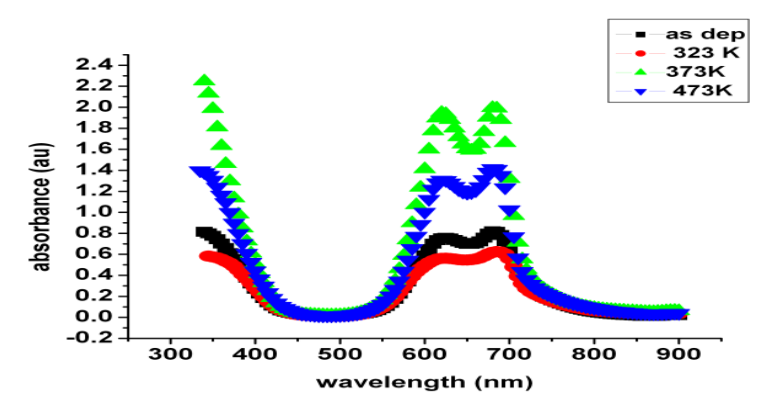

Figure 2. (Optical absorption spectra of ZnTTBPc thin film with different annealing temperature.

Intense band in the blue end of the UV region called B band positioned at $334 \mathrm{~nm}$ is attributed to the deeper $\pi$ levels $\rightarrow$ LUMO transitions, which gave the fundamental absorption edge, while broad band that appeared in the visible region called $\mathrm{Q}$ band, positioned at $681 \mathrm{~nm}$, has been attributed to the $\pi \rightarrow \pi^{*}$ electronic transition from the HOMO (highest occupied molecular orbital) to the LUMO (lowest unoccupied molecular orbital) of 
the $\mathrm{Pc}^{2-}$ ring which gives the exitonic energy. In order to find the optical band gap of ZnTTBPc thin films, the fundamental absorption edge was analyzed using the relation:

$$
\alpha=\alpha_{0}(h v-E g)^{n}
$$

$\mathrm{n}$ determines the type of transition, $\mathrm{n}$ can take values $1 / 2$ and $3 / 2$ for allowed and forbidden transitions respectively [19]. A linear fit is obtained for $n=1 / 2$, indicating the existence of a direct gap. A graph is drawn with $\alpha^{2}$ vs.hv from which $\mathrm{E}_{\mathrm{g}}$ can be obtained. The plots of $\alpha^{2}$ vs.hv for ZnTTBPc thin films of thickness $250 \mathrm{~nm}$ is given in figure 3. The extrapolation of the graphs to $\alpha^{2}=0$ yields the optical band gapE $E_{g}$. The values of optical band gap of ZnTTBPc are collected in Table. 1

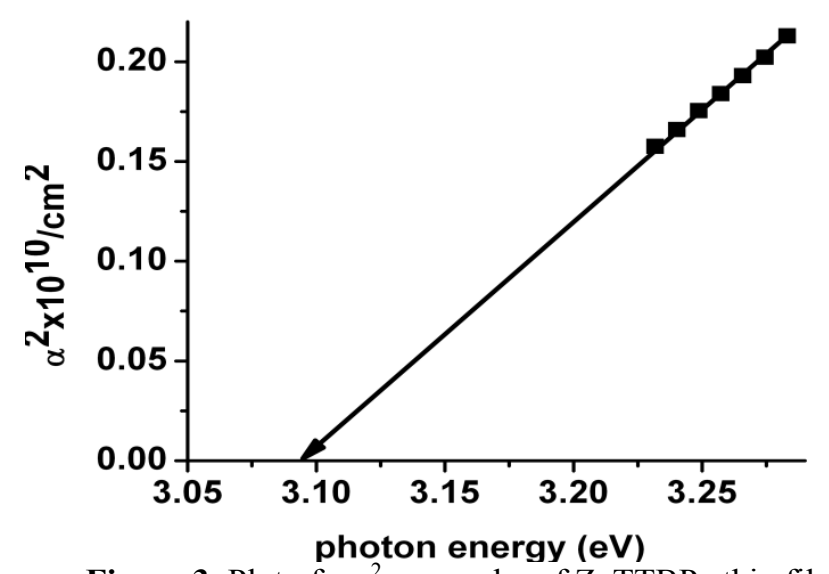

Figure 3. Plot of $\alpha^{2}$ versus hv of ZnTTBPc thin film.

The optical band gap was determined as $3.09 \mathrm{eV}$ within the accuracy of $\pm 0.01 \mathrm{eV}$. The value of band gap energy does not change considerably for higher annealing temperature. Values of the energy gap for as deposited and annealed films are depicted in Table 1.

Table 1. Band gap energy of as deposited and annealed ZnTTBPc thin films.

\begin{tabular}{|c|c|}
\hline Annealing temperature $(\mathrm{K})$ & Band gap energy $(\mathrm{eV})$ \\
\hline As deposited & 3.09 \\
323 & 3.1 \\
373 & 3.1 \\
423 & 3.09 \\
523 & 3.1 \\
\hline
\end{tabular}


Due to weak Van der Waal's interaction between the molecules in the film, their optical properties are not significantly changed when compared with free molecules.

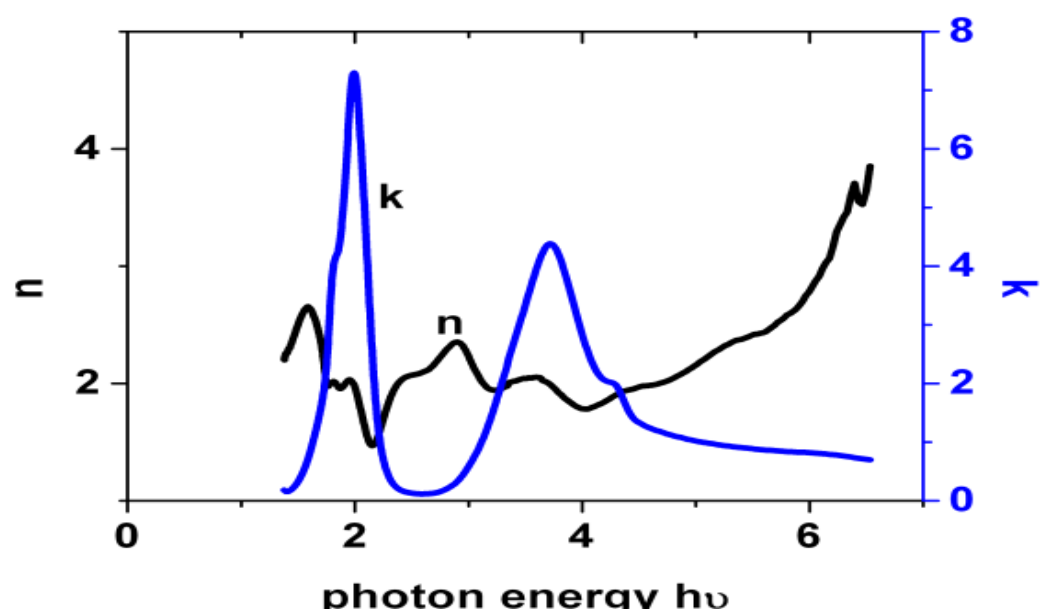

Figure 4. The refractive index and the extinction coefficient of ZnTTBPc as a function of photon energy.

The most accurate method for determining the energy band structure of semi conductors is one based on investigating the spectral distribution of both the refractive index $n$ and the absorption index $\mathrm{k}$. The reflectivity $\mathrm{R}$ of an absorbing medium of indices $\mathrm{n}$ and $\mathrm{k}$ in air for normal incidence is given by

$$
R=\frac{(n-1)^{2}+k^{2}}{(n+1)^{2}+k^{2}}
$$

Where $\mathrm{n}$ is the refractive index, $\mathrm{k}$ is the extinction coefficient $(\mathrm{k}=\alpha \lambda / 4 \pi), \lambda$ is the wavelength.

The variation of the refractive index and the extinction coefficient with photon energy for ZnTTBPc films is shown in figure 4. The rise and fall in the extinction coefficient and refractive index is due to the variation in the absorbance.

The optical properties of the film are characterized by complex refractive index ( $N=n-i k)$ and complex dielectric constant $\left(\varepsilon=\varepsilon_{1}-i \varepsilon_{2}\right)$. If the refractive index $\mathrm{n}$ and extinction coefficient $\mathrm{k}$ are known, the real and imaginary parts of dielectric constants $\left(\varepsilon_{1}\right.$ and $\varepsilon_{2}$ ) of the film can be also estimated.

$$
\begin{gathered}
\varepsilon_{1}=n^{2}-k^{2} \\
\varepsilon_{2}=2 n k
\end{gathered}
$$

The real part $\varepsilon_{1}$ generally relates to the dispersion, while the imaginary $\varepsilon_{2}$ gives a measure of the dissipation rate of the wave in the medium.

The dependence of photon energy $\varepsilon_{1}$ and $\varepsilon_{2}$ is plotted in Figure 5 . 


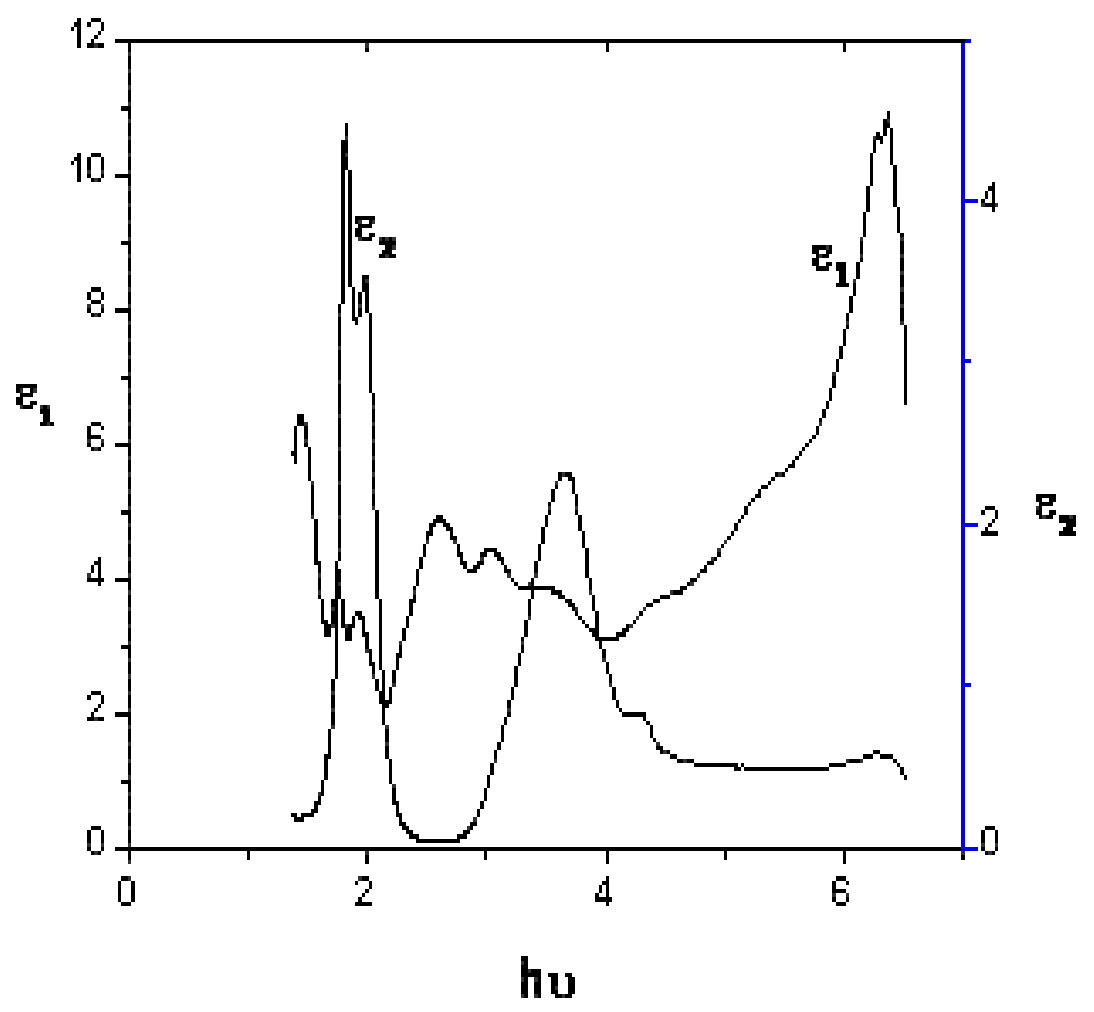

Figure 5. The real and imaginary parts of the dielectric constant of ZnTTBPc as a function of its photon energy.

\section{Electrical studies}

Figure (6) gives the plot of $\ln \sigma$ vs.1000/T for the ZnTTBPc thin films at different annealing temperature. Hot probe method was used to find the type of charge carriers. The charge carriers in ZnTTBPc are found to be p-type. The activation energy of the films were calculated from the slope of the Arrhenius plot of conductivity (Figure 6) using the relation.

$$
\sigma=\mathrm{A} \exp \left(-E_{1} / k T\right)+\mathrm{B} \exp \left(-E_{2} / k T\right)+\ldots
$$

Where $\sigma$ is conductivity, $E_{1}$ is the intrinsic energy gap and $E_{2}$ is the activation energy needed to excite the carriers from the corresponding trap levels to the conduction band[20], $\mathrm{k}$ is the Boltzmann constant, $\mathrm{T}$ is the absolute temperature $\mathrm{A}$ an $\mathrm{B}$ are constants. 


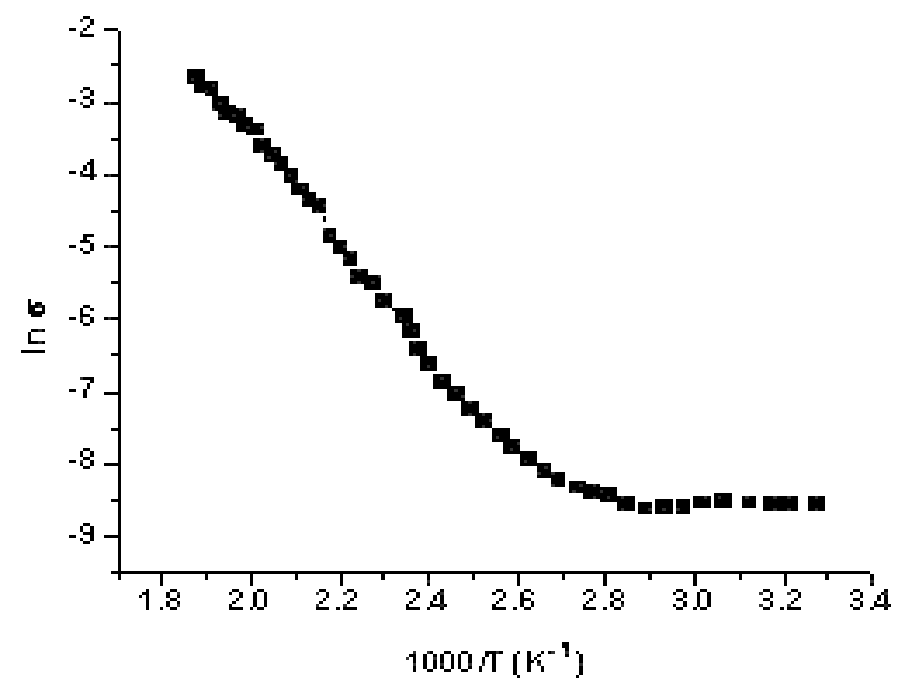

Figure 6. $\ln \sigma$ vs.1000/T of ZnTTBPc thin films.

It is seen from the plot that for all the films, the conductivity is a linear function of the reciprocal of temperature. Linearity of the plot is nearly same for all the films.

The resistance of the film was measured using a Keithley programmable electrometer. The electrical conductivity $\sigma$ of the film of resistance R, length 1 , breadth $b$ and thickness $t$ are given by

$$
\sigma=l / R b t
$$

The activation energies in the intrinsic region $\left(E_{1}\right)$ and impurity scattering regions $\left(E_{2}\right)$ are given in Table 2 .

Table 2. Activation energies of ZnTTBPc thin films.

\begin{tabular}{|c|cc|}
\hline Annealing temperature(K) & \multicolumn{2}{|c|}{ Activation energy(eV) } \\
\cline { 2 - 3 } & $\mathrm{E}_{1}$ & $\mathrm{E}_{2}$ \\
\hline As deposited & 0.66 & 0.08 \\
473 & 0.62 & 0.17 \\
423 & 0.63 & 0.02 \\
473 & 0.64 & 0.05 \\
523 & 0.62 & 0.12 \\
\hline
\end{tabular}


From the table we can seen that as the annealing temperature increases the activation energy $E_{1}$ increases from 0.62 to 0.64 , there after it decreases. Also $E_{2}$ is found to increases $423 \mathrm{~K}$.

\section{Surface morphology}

Surface morphological studies were carried out using the scanning electron microscopy. From these images it is clear that, the surface morphology is different. Figure 7(a) shows that the film deposited at room temperature had smooth featureless surface with small crystal grain structure. However when the film is annealed at higher temperature we get the fibre like structure seen in figure7(c).

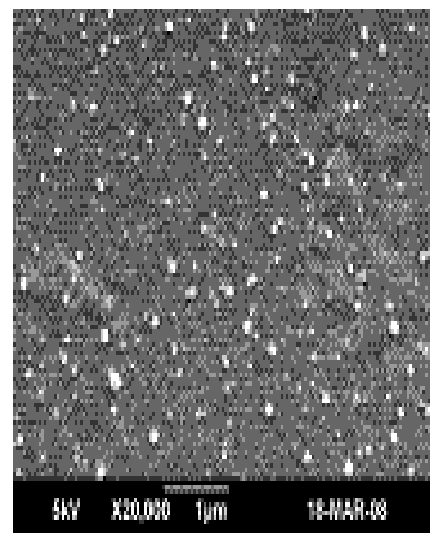

(a)

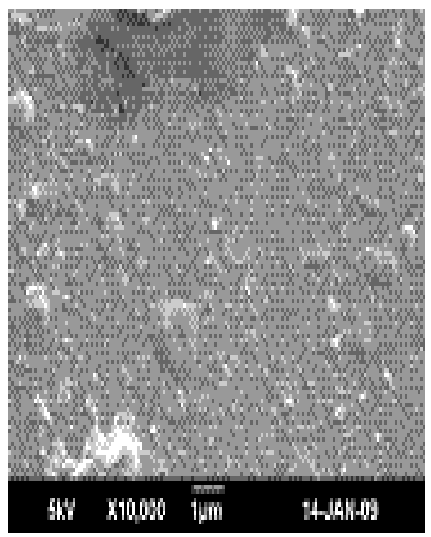

(b)

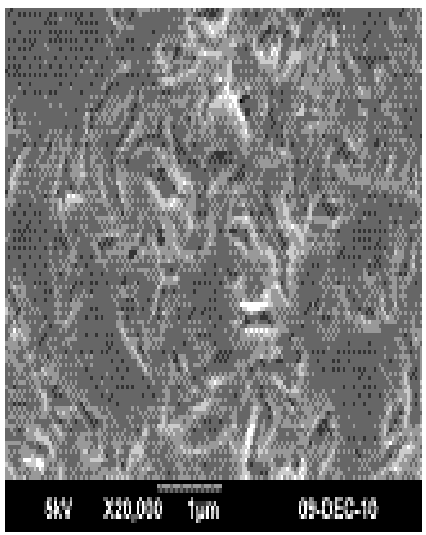

(c)

Figure 7. Surface morphology of as deposited film (a), 373K annealed film (b) and 523K annealed film(c).

\section{Summary and Conclusions}

The effects of air annealing on the optical, electrical and surface morphology of the ZnTTBPc thin films were investigated. The optical properties of ZnTTBPc thin films deposited at room temperatures was studied in the spectral range $300-900 \mathrm{~nm}$. The two main absorption bands of metal phthalocyanine are ascribed to the $\pi$ to $\pi^{*}$ transition. The plots of the refractive index $\mathrm{n}$, and the extinction co-efficient $\mathrm{k}$, with photon energies were studied. The variation of $\varepsilon_{1} \& \varepsilon_{2}$, the real and imaginary parts of the dielectric constant, with the photon energy was also described. From the slope of linear portions of the graph, $\ln \sigma$ vs.1000/T, the activation energies were calculated. The activation energy $\mathrm{E}_{1}$ corresponding to the high temperature region was due to intrinsic carriers. The activation energy $\mathrm{E}_{2}$ corresponds to the extrinsic conduction due to impurity states. Surface morphology is also studied. 


\section{References}

1. Nebesny K, Collins G E and Lee P A Chem. Mater. 1991, 3, 829.

2. Pope M and Swenberg C E, Electronic Process in Organic Crystals, Clarendon Press, Oxford, 1992.

3. Kamath G B, Joseph and Menon C S Mater. Lett. 2002, 57, 730.

4. Leznoff C C and Lever A B P, Phthalocyanines: Properties and Applications, VCH: New York, 1993, 3.

5. Gu D, Chen Q, Tang X, Gan F, Shen S, Liu K and Xu H, Opt. Commun. 1995, 121, 129.

6. Haisch P, Winter G, Hanack M, Luer L, Egelhaaf H J and Oelkrug D, Adv. Mater. 1997, 9, 316.

7. Ao R, Kilmmert L and Haarer D Adv. Mater, 1997, 7, 495.

8. El-Nahass M M, Farag K F, Abd-El-Rahman A A M and Darwish A, Optics \& Laser Technology. 2005, 37, 513.

9. Mori T, Mitsuoka T, Shii M I, Fujikawa H, Taga Y, Appl. Phys. Lett. 2002, 80, 3895.

10. Rajesh K R, Menon C S, Semicond. Sci. Technol. 2005, 20, 464.

11. Ambily S, Menon C S, Thin Solid Films.1999, 347, 288.

12. Rajesh K R, Menon C S J. Non-Cryst. Solids . 2005, 351, 2420.

13. Gopinathan T G, Menon C S, E -J Chem. 2004, 5, 236.

14. Ding H M, Erokhin Y, Ram M K, Paddew S, Valkov L, Nicolini C, Thin Solid Films. 2000, 379, 286.

15. Richardson T H, Dooling C M, Worsfold O, Jones L H, Kato K, Shinbo K, Kancko F, Treggoningd R, Vgsotsky M O, Hunter C A, Thin Solid Films. 2001, 393, 266.

16. Perry J W, Mansour K, Lee I.-Y S, Wu X -L, Bedworth P V, Chen C -T, Ng D, 1996, 273, 1536.

17. Maissel L I, Glang R Handbook of Thin Film Technology, McGraw-Hill: New York, 1983.

18. Ambily S, Menon C S, Thin Solid Films. 1999, 347, 288.

19. Khan G A and Hogarth C R J. Mater. Sci. 1991, 26, 412.

20. Muller M A, Mihai I Cand Muller L P Phys. Status Solid A. 1971, 4, 479. 


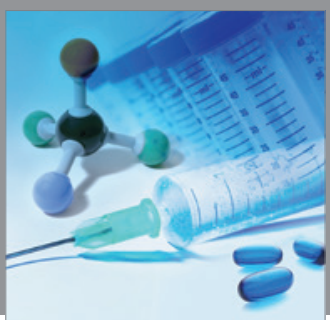

International Journal of

Medicinal Chemistry

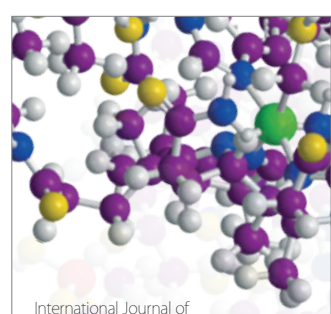

Carbohydrate Chemistry

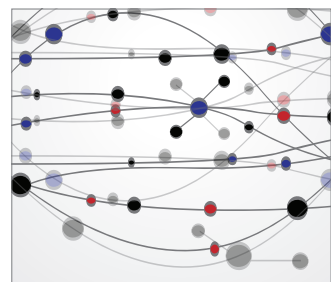

The Scientific World Journal
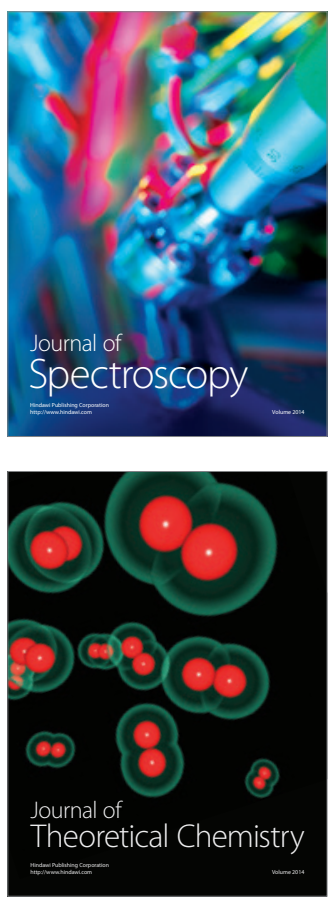
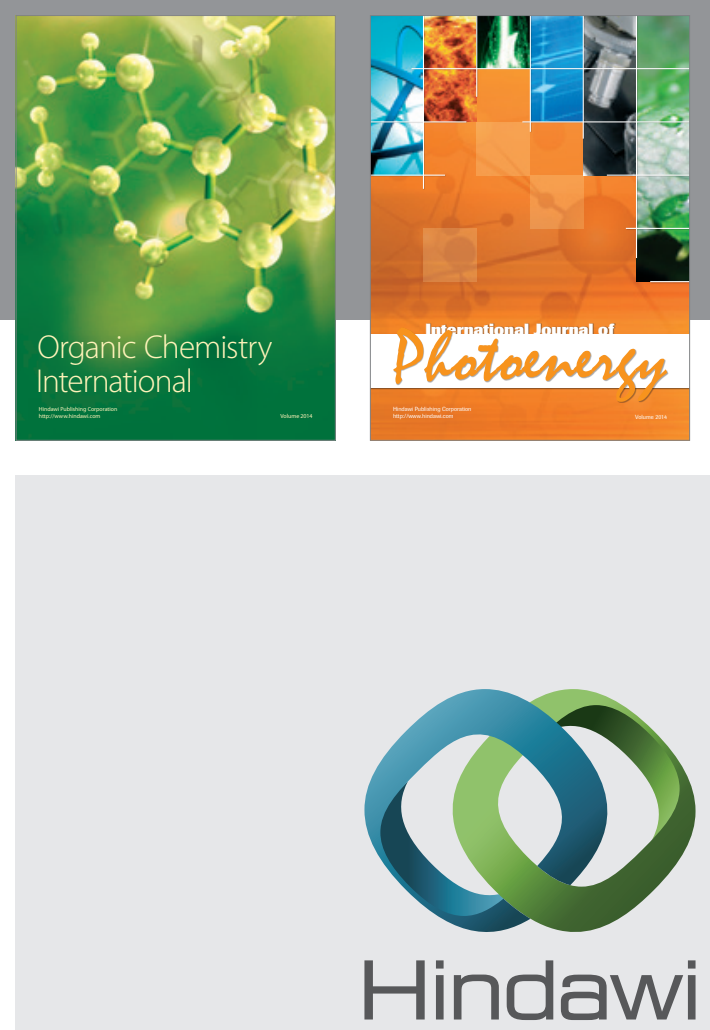

Submit your manuscripts at

http://www.hindawi.com
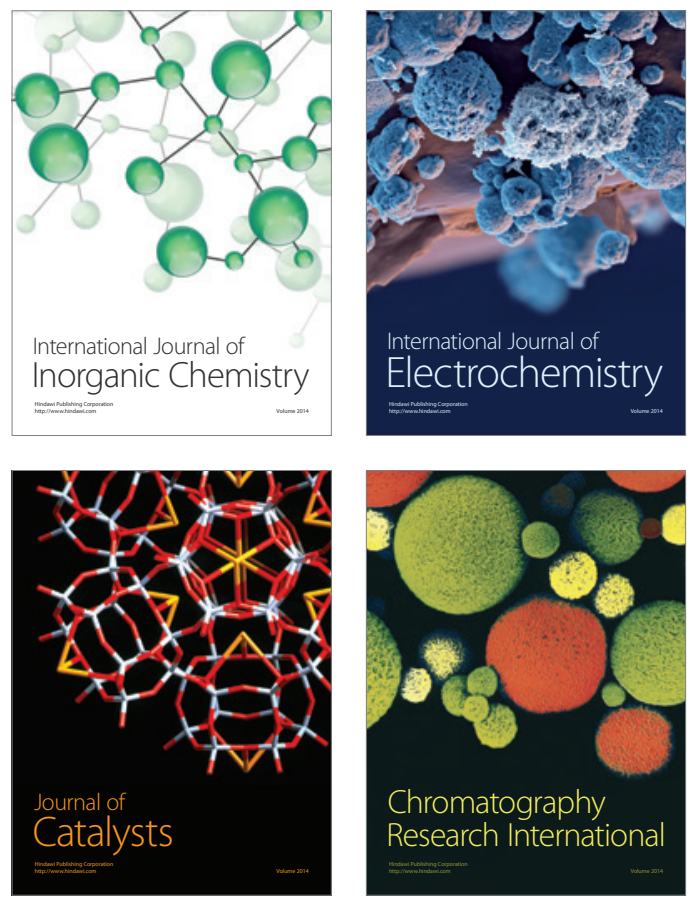
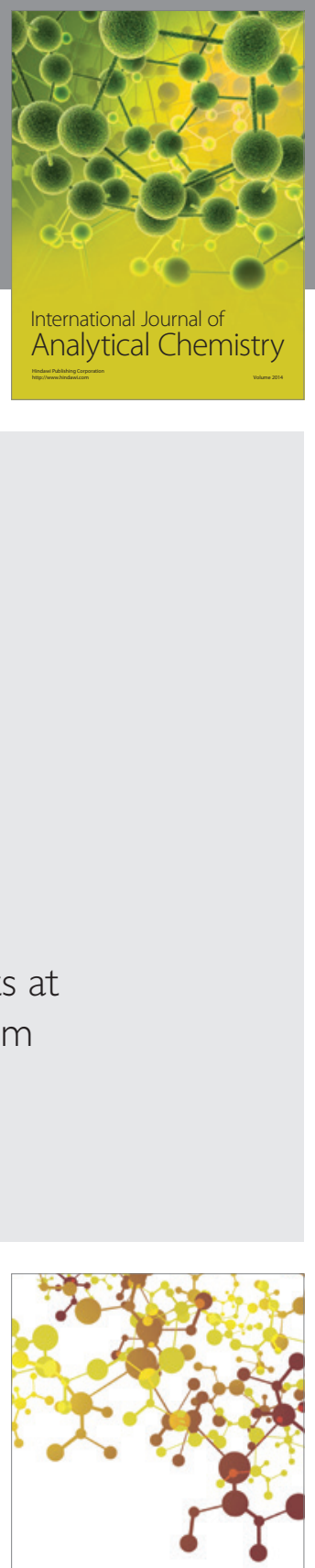

Journal of

Applied Chemistry
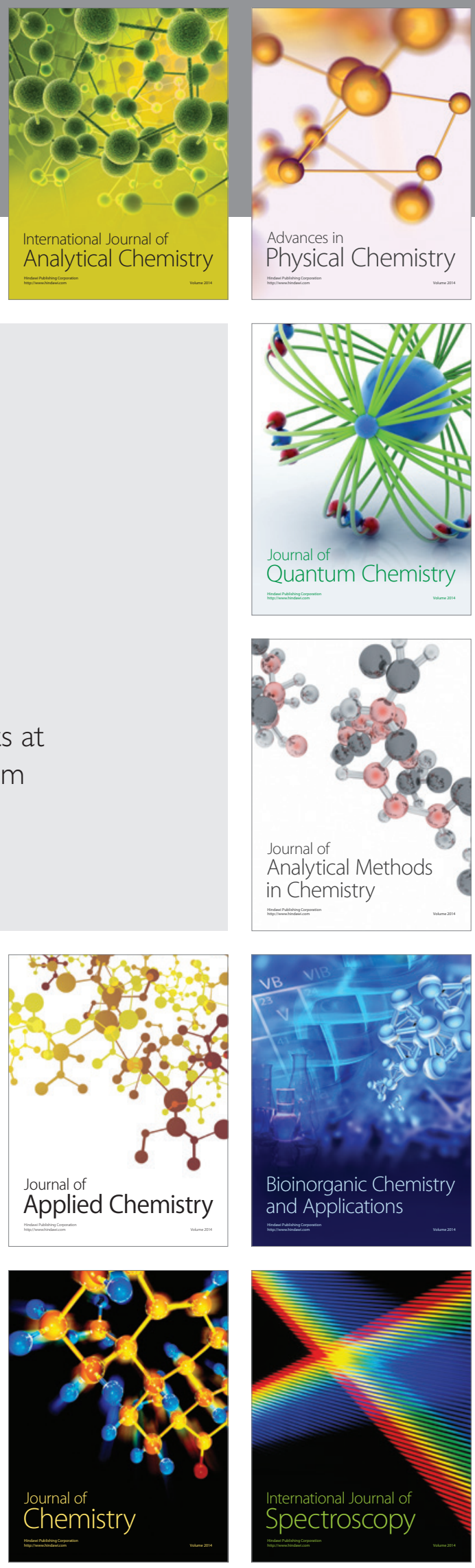